\title{
LYMPHANGIOMA OF SOFT PALATE: A CASE REPORT
}

\author{
S. Indira Devi ${ }^{1}$, Manish Kumar Gupta르, K. V. N. Durga Prasad ${ }^{3}$, T. Shankar ${ }^{4}$, Juveria Majid ${ }^{5}$
}

\section{HOW TO CITE THIS ARTICLE:}

S. Indira Devi, Manish Kumar Gupta, K. V. N. Durga Prasad, T. Shankar, Juveria Majid. "Lymphangioma of Soft Palate: A case report". Journal of Evolution of Medical and Dental Sciences 2014; Vol. 3, Issue 61, November 13; Page: 13607-13612, DOI: $10.14260 /$ jemds/2014/3815

ABSTRACT: INTRODUCTION: Lymphangioma is a benign hamartomatous tumor of lymphatic vessels. Described for the first time by Redenbacher in 1828, currently the lymphangiomas are classified as malformations and not as neoplasms. ${ }^{1}$ It has a marked predilection for the head and neck region, at submandibular and parotid area. Its occurrence at oral cavity is rare and it is most commonly identified at the anterior two thirds of the tongue. Its occurrence in soft palate is very rare. Lymphangioma is observed on birth or manifests before 2 years of age ${ }^{2}$.In the case reported here, the lesion developed in a patient older than the common age group. At this location, it is clinically characterized as transparent and generally grouped vesicles ${ }^{3,4}$ which can be red or purple or blue. The deep lesions appear as nodular masses of variable color and superficial texture. It can be classified according to the size of vessels into three types: capillary, cavernous, and cystic lymphangioma. ${ }^{5}$ Several types of treatment have been suggested; and the most commonly used treatments are: surgical excision, application of carbon dioxide laser, cryotherapy using liquid nitrogen, and sclerosing agents. ${ }^{5}$ CASE PRESENTATION: A female patient aged about 45 years presented with bluish swelling near soft palate. Histopathology confirmed diagnosis of Lymphangioma. DISCUSSION: Windstorm criteria were used to confirm the diagnosis conclusion lymphangioma of soft palate is a rare entity. This study emphasizes the clinical \& histopathological features that should be considered to confirm clinical Diagnosis and indicate the proper management for oral lymphangioma.

KEYWORDS: Lymphangioma, soft palate, histopathology.

INTRODUCTION: Lymphangioma of soft palate is a benign condition and is a rare entity. Recently we encountered a case of swelling of soft palate which turned out be lymphangioma.

CASE HISTORY: A Patient presented with swelling over soft palate and pain since 3 months. The lesion gradually increased to the present size. No h/o trauma.

On intra oral examination, a bluish colored diffuse swelling of size approximately $3 \times 2 \mathrm{cms}$ was seen over left part of soft palate, crossing the midline. On palpation, it was soft to cystic in consistency with few areas palpable as boggy texture. Mildly tender on palpation and ill-defined borders. Mucosa over the swelling has bluish discoloration. Mucosa over Surrounding structures and retro molar trigone was normal.

Patient was subjected for Fine Needle Aspiration Cytology (FNAC), which concluded as Retention Cyst. Computerized Tomography scan was done to see extent of the lesion, any bony indentations or erosion. No bony indentation or erosion was found. 


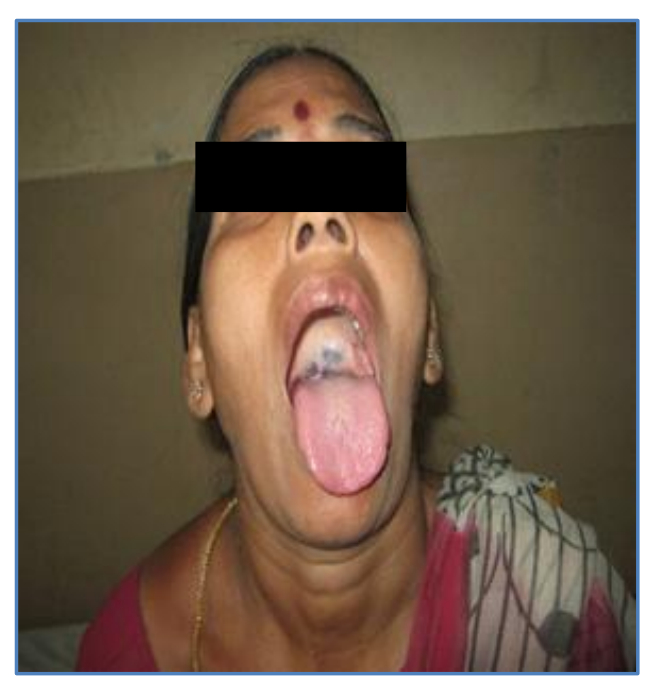

\section{A diffuse bluish colored swelling of size $3 \times 2 \mathrm{cms}$ seen over left side of soft palate}

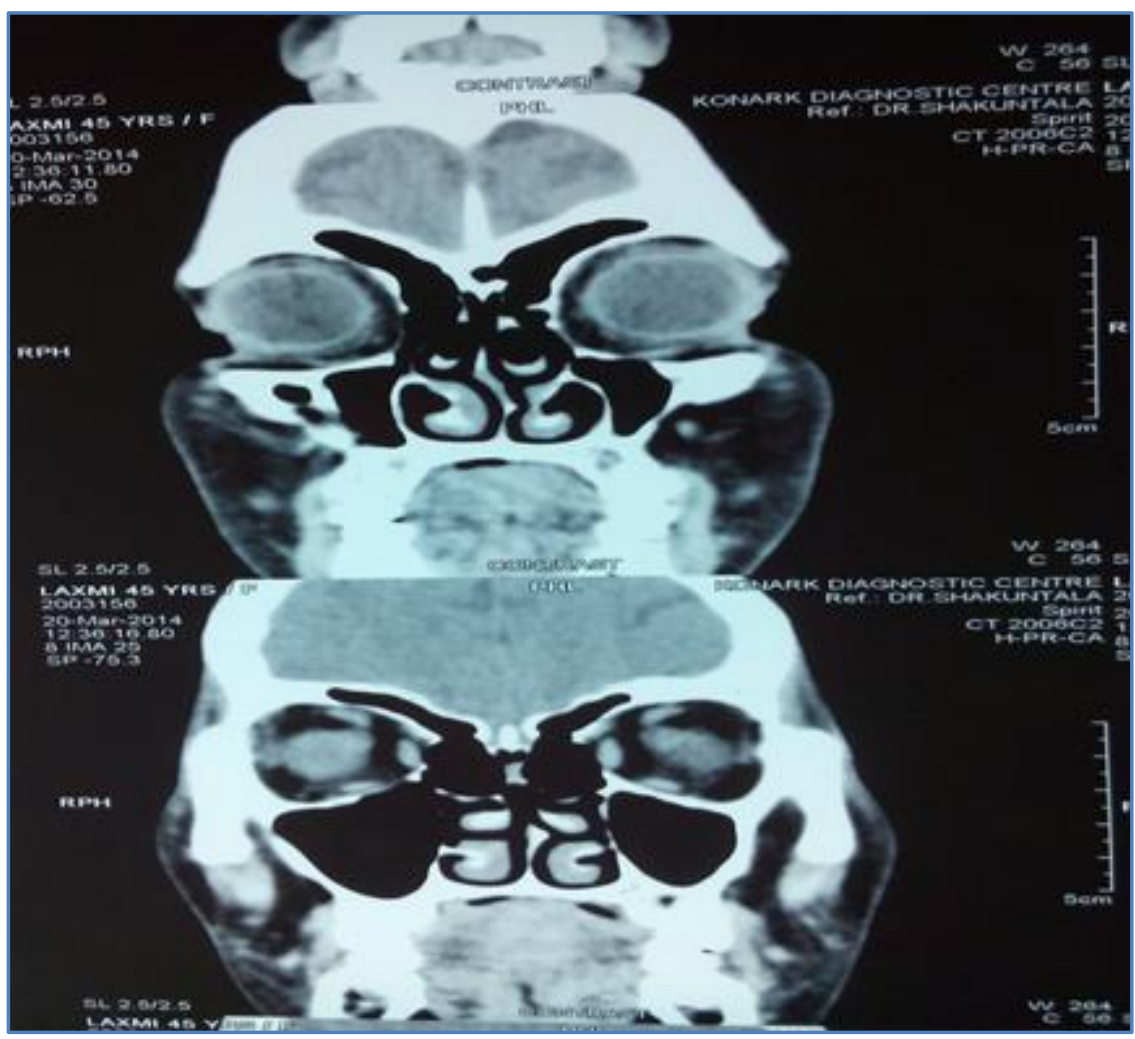

CT scan not showing any bony erosion

Patient was taken up for excision of the mass under GA. The lesion was excised in toto and with intact mucosal flap technique, wherein mucosa was incised, mass removed, Homeostasis Secured. Post operatively patient was put on Ryle's tube feeding for 5 days. There was partial necrosis of the flap on $5^{\text {th }}$ postoperative day. The necrosed mucosa debrided and post op antibiotic coverage and gargling with betadine solution was advised. Later ryles tube removed, oral intake of 


\section{CASE REPORT}

food started with liquids and semisolids first. Patient was followed up at intervals of 1 week, later 2 weekly. Complete epithelialization was seen at the end of 6 weeks. No defect in palate was seen.

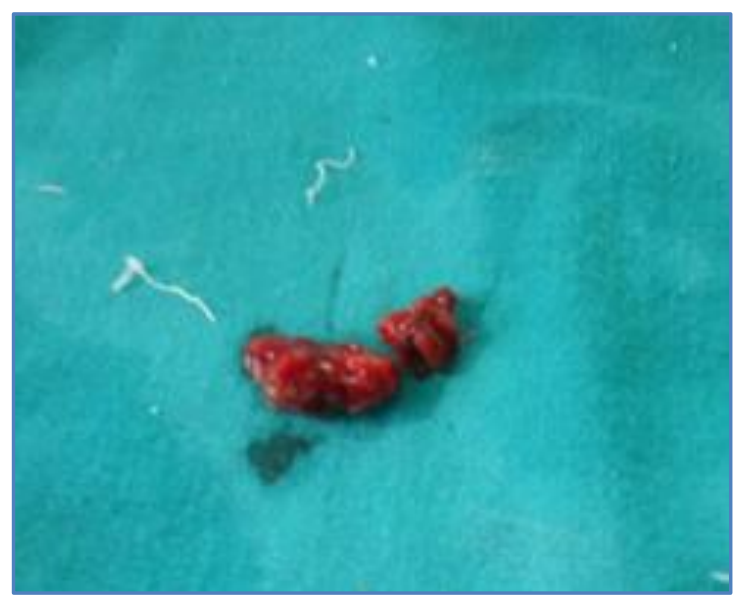

\section{Excised mass}

The lesion excised was sent for histopathological examination. The histological cuts were examined and stained in hematoxylin and eosin, revealing lymphatic vessels of great diameter distributed in a conjunctive tissue poorly organized. Therefore, the histopathological diagnosis confirmed the clinical and surgical diagnosis of lymphangioma.

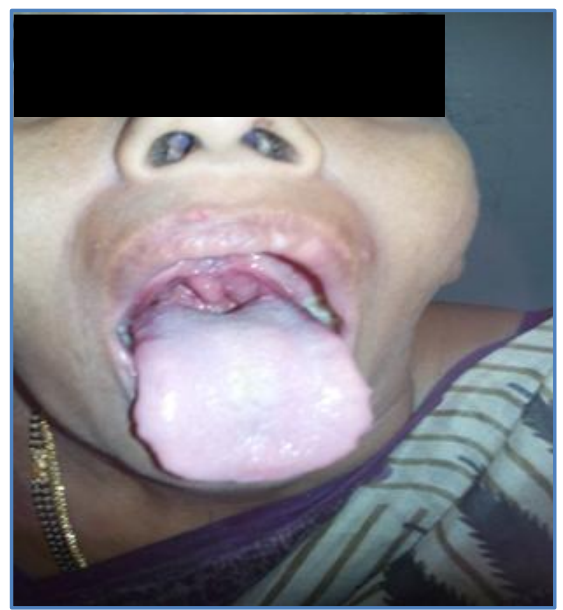

Wound healed well with complete epithelialization and no palatal defect

Patient is being followed from last 3 months. Till date there is no recurrence.

DISCUSSION: Lymphangiomas are hamartomatous, congenital malformations of the lymphatic System.1,2,6 They are believed to arise from lymph sac sequestration and enlarge due to inadequate drainage, from lack of communication with the central lymphatic channels or excessive secretion of lining cells. ${ }^{3}$ 
Lymphangioma is observed at birth or mostly presents below 2 years ${ }^{1}$. In the case reported here, the lesion developed in a patient older than the common age group which is infrequent.1,2, 3,4 .

Lymphangioma have a marked predilection for the head and neck region, which accounts for about $75 \%$ of all cases. Lymphangiomas have been classified into ${ }^{1}$ :

- Lymphangioma simplex (capillary lymphangioma) consists of small, capillary-sized vessels

- Cavernous lymphangioma is composed of large, dilated lymphatic vessels

- Cystic lymphangioma (cystic hygroma) exhibits large macroscopic cystic spaces.

This is also classified according to the clinical presentation into macrocystic, microcystic and mixed, combining these two types. ${ }^{1}$

Oral lymphangiomas occur at various sites, but are most frequently found on the anterior two-thirds of the tongue, where they often result in macroglossia. The lesion can also present in the palate, buccal mucosa, gingival, and lips. Uncommon occurrences involve the soft palate and retromolar region. ${ }^{1,2,6}$ Clinically, the lesions present superficially as a bluish or purple swellings with diffuse margins. In oral cavity, the dense conjunctive tissue and the presence of the muscles do not allowed the vessels great expansion. Consequently, the most common intraoral type is cavernous lymphangioma. ${ }^{1}$

The diagnosis of lymphangiomas is not difficult, being mainly clinical. In lesions with atypical clinical features, a definitive diagnosis should be made through FNA Cyotology or biopsy and histopathological examination, along with imaging studies which are very useful in confirming the diagnosis. ${ }^{1}$ Vascular malformations do not contain hyperplastic cells but consist of progressively enlarging aberrant and ectatic vessels composed of a particular vascular architecture such as veins, lymphatic vessels, venules, capillaries, arteries, or mixed vessel types. ${ }^{1,3}$

Vascular malformations are appropriately named by their predominant vessel type (e.g., venous malformations, arteriovenous malformations). In this case it was due to lymphatic vessels and hence it is termed as lymphatic malformation.

While multiple therapeutic modalities have been described for the treatment of deep lymphangiomas, such as surgical excision, cryotherapy, electro cauterization, schlerotherapy, steroids administration, embolization, and laser therapy surgical excision has been the best alternative for lesions presenting localized growth ${ }^{1,2,5,7,8}$

Because the lesions described in this case report exhibited a superficial location, we opted for the surgical removal. After regular follow-up, no sign of relapse was identified.

CONCLUSION: Lymphangiomas of oral cavity are rare particularly of soft palate. Superficial and localized lesions can be treated by conservative surgical excision. For proper therapy and correct diagnosis the complete knowledge is essential. 


\section{CASE REPORT}

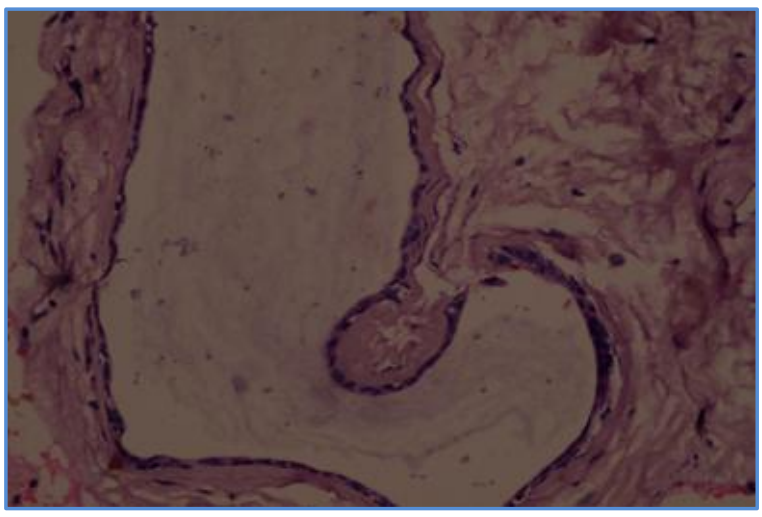

Cystic lesion lined by thin flattend epithelium (HE 40X)

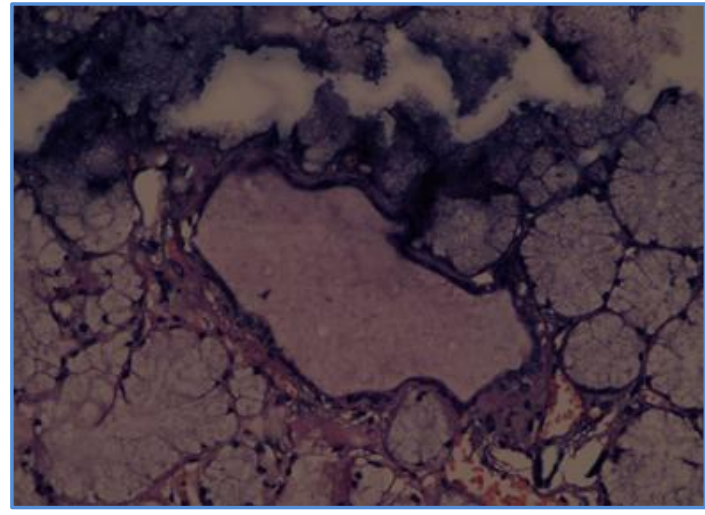

Minor salivary gland with cyst lined by thin flattend epithelium (HE 40X)

\section{REFERENCES:}

1. Lymphangioma Circumscriptum in an Adult: An Unusual Oral Presentation C. Ganesh, G. S. Sangeetha, Vivek Narayanan and T .N. Umamaheswari. Available from

URL: http://www.ncbi.nlm.nih.gov/pmc/articles/PMC3823387/Article in Journal of clinical imaging science 2013; 3: 44, published online Oct 292013.

2. Lymphangioma of the Palate: A Case Report. Vijayalakshmi S Kotrashetti, MDS; Alka D Kale, MDS; and Yasmin Satpathy, MDS Jun 2010; 4 (2). Dentistry India.

3. Fatih Mehmet Coskunses, Funda E. Tugcu, Ismail Doruk Koçyigit, Ozkan Ozgul, Secil Nigar Karadeniz. Lymph Angiom A of bucc AL mucos A - A cAse report. International Journal of Dental clinics.2004; 4 (1): 50 -51.

4. Mandel L. Parotid area lymphangioma in an adult:oral and maxillofacial surgery. 2004; 62 (10): 1320-3.

5. Marcelo Gadelha Vasconcelos, Bruna Camara Santos, Luciana Cristina Peixoto Lemos, Case Report on Oral Lymphangiomas. RSBO.2011 July-Sep; 8 (3)-352-6.

6. Mousumi Goswami, Sanjay Singh, S Gokkulakrishnan, Amit Singh Lymphangioma of the tongue Natl J Maxillofac Surg. 2011 Jan-Jun; 2 (1): 86-88.

doi:10.4103/0975-5950.85862National journal of maxillofaial surgery.

7. Edwards SP, Helman JI. Oral lymphangioma. E Medicine Web site. http://emedicine.medscape.com/article/1076948 -overview. Accessed June 9, 2010.

8. Ikeda H, Fujita S, Nonaka M, et al. Cystic lymphangioma arising in the tip of the tongue in an adult. Int J Oral Maxillofac Surg. 2006; 35 (3): 274-276. 


\section{AUTHORS:}

1. S. Indira Devi

2. Manish Kumar Gupta

3. K. V. N. Durga Prasad

4. T. Shankar

5. Juveria Majid

\section{PARTICULARS OF CONTRIBUTORS:}

1. Formerly Professor, Department of ENT, Osmania Medical College, Hyderabad.

2. Assistant Professor, Department of ENT, Osmania Medical College, Hyderabad.

3. Assistant Professor, Department of ENT, Osmania Medical College, Hyderabad.

4. Professor, Department of ENT, Osmania Medical College, Hyderabad.
5. Post Graduate, Department of ENT, Osmania Medical College, Hyderabad.

NAME ADDRESS EMAIL ID OF THE CORRESPONDING AUTHOR:

Dr. Manish Kumar Gupta,

H. No. 564, Road No. 12,

Banjara Hills,

Hyderabad-500034.

Email: drmanishgupta003@gmail.com

Date of Submission: 11/10/2014.

Date of Peer Review: 13/10/2014.

Date of Acceptance: 07/11/2014.

Date of Publishing: 13/11/2014. 